\title{
Estudio intertextual sobre la persuasión de la palabra en Encomio de Helena y La Celestina
}

Intertextual study on the persuasion of the word in Commendation of Helena and La Celestina

Endika Basáñez Barrio

Departamento de Filología Hispánica, Románica y Teoría de la Literatura Universidad del País Vasco UPV/EHU

España) (endika.basanez@ehu.eus)

RESUMEN: El presente artículo pretender vincular dos obras canónicas de las literaturas griega y española en un ejercicio de intertextualidad que se centra en la experiencia de la persuasión de la palabra que se ejerce sobre diversos actantes pertenecientes a sendos textos. En última instancia se pretende, así, poner en relieve que el análisis comparatístico permite aproximar la génesis de la literatura universal a pesar de los diferentes contextos nacionales y socio-políticos que separan las producciones artísticas, lo que desdibuja la idea de literaturas nacionales y aspira a abrir nuevas posibilidades de exploración del arte en forma de palabra escrita.

PALABRAS CLAVE: Literatura griega, Literatura española, Intertextualidad, Sofistas, La Celestina.

\begin{abstract}
The main aim this paper tries to focus on is the idea of comparing two different pieces of art, being both written in two diverse centuries and socio-political contexts: one of them in the ancient Greek and the other one in medieval Spain. If we get closer to this idea, we are trying to highlight the existence of new approaches to universal literature when it comes to comparative research, which might help to erase the concept of "national" literatures.
\end{abstract}

KEYWORDS: Greek literature, Spanish literature, Intertextuality, Sophism, The Celestina. 
La palabra es un poderoso soberano que, con un cuerpo pequeñisimo y completamente invisible, lleva a cabo obras sumamente divinas.

Gorgias de Leontinos

Lo cierto es que la simple lectura del Encomio de Helena y la Defensa de Palamedes nos encaminó hacia la elaboración de este artículo en tanto que, en ambos, Gorgias de Leontinos prueba su valor como maestro de retórica defendiendo a través de sus discursos a Helena y Palamedes, labor teóricamente imposible a juzgar por el recuerdo asociado a la traición de ambos en el acervo cultural de la sociedad griega (Sechi Mestica, 2007, pp. 127-205.). Dado que nuestro trabajo debe ser conciso, decidimos centrarnos en el estudio del Encomio y, más específicamente, en uno de los argumentos a los que Gorgias recurre para justificar la huida a Troya de Helena: la persuasión a través de la palabra. El sofista exculpa así a la hija de Zeus y tacha de injusta la mala fama que la historia le ha atribuido, ya que este pone en relieve que el culpable de la huida de Helena no es ella, sino quien la encantó a través del uso de la palabra. Es precisamente esta razón, en la que el sabio se recrea con detalle y especial atención, lo que nos pareció ciertamente anecdótico, ya que, si bien la inclusión sobre los efectos de la palabra en el oyente no deja de ser un juego retórico en el que poner en marcha sus claras habilidades discursivas, el contenido que encierra este argumento se volvería a repetir, bajo nuestra visión, veinte siglos después en una de las obras más celebradas de la literatura española: La Celestina. En efecto, la recreación del proceso de encantamiento que sufriera Helena a través de la persuasión de la palabra de Paris que Gorgias recoge en su obra, bien puede ser apreciado en el texto de Rojas a través de los encuentros entre Celestina y Melibea, donde la alcahueta acaba por hacerse con la voluntad de la joven a través del hábil uso de la palabra. De esta forma, Melibea quedaría excluida de toda culpa de su funesto destino (al igual que Helena), ya que no actuaría bajo su voluntad, sino que se habría visto sometida a los efectos de la palabra de la tercera.

La lectura del discurso de Gorgias despertó así en nosotros una relación de intertextualidad literaria que relacionaba el proceso de encantamiento que la palabra habría producido en Helena, según la visión del sofista, y exactamente la misma característica analítica sólo que a través de diferentes actantes: Celestina y Melibea. La idea de comparar dicho proceso en ambas obras literarias nace, por tanto, del conocimiento y lectura de sendos textos, de forma que si bien puede 
parecer un trabajo arriesgado (por la ausencia de bibliografía al respecto que avale nuestra hipótesis), nos plantea todo un reto comparatístico (ya que intertextual) al que hacemos frente.

Bien es cierto que la elaboración de los discursos recogidos como Encomio de Helena y Defensa de Palamedes (si bien ambos pueden ser interpretados como defensas jurídicas a personajes cuyo recuerdo la historia ha connotado negativamente) pasan a convertirse en un muestrario de las dotes retóricas y discursivas del autor de las mismas, ya que los sofistas, sabios del conocimiento, buscaban en su labor un claro afán lucrativo (Martínez, 2007, p. 15). No debemos olvidar, de la misma forma, que la producción de Gorgias es, en gran medida, fruto del gusto y admiración de la sociedad griega por la expresión inteligente del discurso y el uso del ejercicio retórico en la génesis del mismo. De igual modo, la elaboración de La Celestina se vincula con varias interpretaciones ideológicas sobre el tiempo para el que fue escrita, de forma que su estudio actual puede no responder con exactitud al contexto histórico para el que fue creada. No obstante, y si bien es preciso no ignorar los detalles de la génesis de ambas obras literarias, nosotros nos proponemos establecer un análisis comparativo entre el proceso de encantamiento del que, tanto Helena como Melibea, hubieran sido objeto a través de la persuasión de la palabra de Paris y Celestina en las obras literarias apuntadas con anterioridad.

La producción discursiva que nos ha llegado de Gorgias da buen detalle de las dotes retóricas del de Leontinos y, en efecto, el Encomio de Helena muestra cómo el sofista sabía valerse de sus conocimientos sobre la elaboración de discursos y del sabio ejercicio de la retórica para ganarse astutamente el beneplácito de sus oyentes. El Encomio, por tanto, se encuadra en la génesis discursiva llevada a cabo por Gorgias y, por extensión los sofistas, como muestrario del manejo de la sabiduría de la que hacían gala y de la que habían hecho su particular modo de ganarse la vida. Gorgias elabora en su discurso una inteligente combinación de razonamientos lógicos por los cuales Helena tan sólo habría actuado como objeto pasivo de la partida a Troya, por lo cual habría sido, pues, víctima irremediable de su desgracia. En este sentido, el de Leontinos recurre en primer lugar a excusar la partida de Helena a través de dos poderosas razones inevitables como son el deseo de los dioses y el rapto con violencia como motivos del infortunio de la bella fémina:

Y los dioses son algo más fuerte que el hombre por su violencia, su sabiduría y sus demás facultades. Si hay, pues, que atribuir la culpa al azar y a la diosa, hay que liberar a Helena de la infamia. Y si fue raptada con violencia y forzada contra toda ley 
e injustamente ultrajada, es claro que su raptor, al cometer el ultraje, obró con injusticia. Su rapto, en cambio, al hacerla víctima del ultraje, provocó su desventura (Melero Bellido, 2007, pp. 136-7).

De igual modo, Gorgias continúa su discurso apuntando a más argumentos por los cuales Helena se habría visto irremediablemente obligada a partir hacia Troya desligados de su propia voluntad que, en efecto, son aquellos que más nos interesan en nuestro objeto de estudio: la persuasión de la palabra y sus efectos en el oyente. Gorgias, de hecho, se esmera con detalle en establecer una conexión entre el poder embaucador de la palabra y la ausencia de voluntad en Helena, debida, precisamente, a la persuasión de la misma:

Si fue la palabra la que persuadió y engañó su mente tampoco es difícil hacer una defensa ante tal posibilidad y dejarla libre de acusación, del modo siguiente. La palabra es un poderoso soberano que, con un cuerpo pequeñísimo y completamente invisible, lleva a cabo obras sumamente divinas (Melero Bellido, 2007, pp. 137-8).

El sofista, que hace de su discurso una defensa explícita de la partida de Helena aproximando su producción al género judicial y siguiendo la clasificación discursiva aristotélica, establece una tercera razón para exculpar a la joven de su huida basada en esta ocasión en los efectos de la palabra. En efecto, la relación semántica que establece el de Leontinos entre la palabra, la persuasión y el engaño son tres de los elementos clave propios de la gnoseología gorgiana que él se encarga de introducir en su discurso para liberar de cualquier culpa a la hija de Zeus:

Los encantamientos inspirados, gracias a las palabras, aportan placer y apartan el dolor. Efectivamente, al confundirse el poder del encantamiento con la opinión del alma, la seduce, persuade y transforma mediante la fascinación. [...] Por tanto, la fuerza de la persuasión, en la que se originó su forma de pensar -y se originó, desde luego, por necesidad- no admite reproche alguno, sino que tiene el poder mismo de la necesidad. Pues la palabra que persuade al alma obliga, precisamente a este alma a la que persuade, a dejarse convencer por lo que se dice y a aprobar lo que se hace (Melero Bellido, 2007, pp. 139-40). 
La persuasión de la palabra se asemeja por tanto en Gorgias al rapto por la fuerza en tanto que, si bien el uso de la violencia deja a su víctima sin posibilidad de defensa, de igual modo, el encantamiento producido por la persuasión de la palabra deja al oyente ajeno a su voluntad. De esta forma, Gorgias establece un motivo irrefutable que explicaría el porqué de la huida de Helena a Troya que la exculparía de la causa del conflicto bélico posterior: el encantamiento de la palabra sobre sí habría confundido su alma, reprobando así toda acción acometida como consecuencia de tal proceso. La posición de Gorgias al respecto se radicaliza aún más en su discurso, de forma que establece una exposición gradual sobre los efectos de la persuasión de la palabra en Helena, finalizándola en las consecuencias acarreadas por la palabra a modo de fármaco sobre el cuerpo:

La misma relación guarda el poder de la palabra con respecto a la disposición del alma que la prescripción de fármacos respecto a la naturaleza del cuerpo. Pues, al igual que unos fármacos extraen unos humores del cuerpo y otros, otros; y así como algunos de ellos ponen fin a la enfermedad y otros, en cambio, a la vida, así también las palabras producen unas, aflicción; otras, placer; otras, miedo; otras predisponen a la audacia a aquellos que las oyen, en tanto otras envenenan y embrujan sus almas por medio de una persuasión maligna. Que ella, pues, si fue persuadida por medio de la palabra, no cometió ninguna falta, sino que fue víctima de circunstancias adversas, ha quedado ya demostrado (Melero Bellido, 2007, pp. 141).

La fuerza de la palabra sobre aquel que la oye acaba así con su voluntad activa y confunde su alma, de forma que este reprueba acciones (que de otra manera no haría) a través del encantamiento al que se ve sometido. Helena, por tanto, quedaría totalmente exenta de toda culpa ante su partida a Troya y el error residiría únicamente en aquel que la confundió, embaucó y engañó a través de la persuasión de la palabra: Paris. De igual modo, el tratamiento de la seducción que ejecuta la palabra es especialmente evidente en la obra de Rojas en las dos escenas de encuentro entre la vieja alcahueta, Celestina, y Melibea: actos cuarto y décimo (primer y segundo encuentro respectivamente). El análisis de los efectos de la palabra de Celestina sobre la voluntad de Melibea pondrá de manifiesto que bien puede interpretarse entre ambas producciones un proceso de intertextualidad a través del tratamiento de la palabra y sus efectos en el oyente (Helena en el caso del Encomio, y Melibea en Celestina). Nuestro objeto de estudio en el texto se centra así en los dos encuentros entre la joven Melibea y la astuta Celestina, ya que, bajo nuestra perspectiva analítica, la tercera acaba por hacerse con la voluntad de Melibea a lo largo de sus encuentros a través del uso de 
la palabra y su persuasión, motivo que Gorgias emplea para exculpar a Helena como causante de la Guerra de Troya y que nosotros emplearemos para exculpar a Melibea de su triste sino. En efecto, la voluntad de Melibea en el primer encuentro y en el segundo, tras haber sido sometida ya a los efectos de la palabra de Celestina, es totalmente opuesta en relación a su actitud hacia Calisto. En el primer encuentro con Celestina, Melibea (que ya se había topado con Calisto en el huerto de su padre, Pleberio, cuando el joven iba detrás de su halcón), rehúye oír hablar de Calisto, no siente ningún interés hacia él y tan sólo desea deshacerse de la vieja alcahueta y que ésta dé por finalizada su visita. Celestina, que se presenta en casa de la joven con la excusa de pedirle a ésta el cordón que ciñe su cintura y una oración de Santa Polonia para curar a un enfermo, es buena sabedora del poder de la persuasión de la palabra y emplea todo tipo de figuras retóricas, citas, referencias filosóficas, consejos médicos y diversos argumentos de distinta índole para hacerse con la voluntad de Melibea y conseguir así su acometido, ya que Calisto había sido generoso con ella con el fin de que la vieja le consiguiera el amor de la joven. Y, en efecto, Celestina pone en marcha la ejecución de diversos discursos que juegan con el estado anímico y sentimental de Melibea y la llevan, en última instancia, a enamorarse perdidamente de quien en principio rehusaba saber. La táctica más evidente en el discurso de Celestina se centra en mostrase esquiva en su mensaje, para así despertar el interés de Melibea, ya que, cuanto menos clara se muestra Celestina en relación al motivo de su visita, más interés despierta en la joven:

MELIBEA.- Pide lo que querrás, sea para quien fuere.

CELESTINA.- Yo dexo vn enfermo a la muerte, que con sola una palabra de tu noble boca salida, que le lleue metida en mi seno, tiene por fe que sanará, según la mucha deuoción tiene en tu gentileza.

MELIBEA.- Vieja honrrada, no te entiendo, si mas no declaras tu demanda. Por vna parte me alteras e prouocas a enojo; por otra me mueues a compasión. No te sabría boluer respuesta conueniente, según lo poco, que he sentido de tu habla. Que yo soy dichosa, si de mi palabra ay necessidad para salud de algún cristiano.[..] Assí que no cesses tu petición por empacho ni temor.

CELESTINA.- El temor perdí mirando, señora, tu beldad. Que no puedo creer que en balde pintasse Dios vnos gestos más perfetos que otros, más dotados de gracias, más hermosas faciones; sino para fazerlos almazén de virtudes, de misericordia, de compassión, ministros de sus mercedes e dádiuas, como a ti [...] ¿Por qué no daremos parte de nuestras gracias e personas a los próximos, mayormente, quando están 
embueltos en secretas enfermedades e tales que, donde está la melezina, salió la causa de la enfermedad?

MELIBEA.- Por Dios, sin más dilatar, me digas quién es esse doliente, que de mal tan perplexo se siente, que su passión e remedio salen de vna misma fuente ( De Roja, 1913, pp. 175-178).

El interés de Melibea va haciéndose así cada vez mayor en relación al motivo de la visita de la vieja alcahueta y, de igual modo, las formas de expresión de Melibea van tornándose cada vez más airadas y radicales, lo que demuestra que el estado anímico y la voluntad de la misma son cada vez menos estables; la palabra de Celestina está logrando de esta forma su objetivo: despertar el interés de Melibea en su mensaje a través de mostrarse ciertamente esquiva e invitar ahora a la joven a pensar en las atractivas cualidades de Calisto y, soterradamente, su unión con él: “CELESTINA.- Bien ternás, señora, noticia en esta cibdad de vn cauallero mancebo, gentilhombre de clara sangre, que llaman Calisto" (De Rojas, 1913, 178).

Es así como Celestina ha conseguido hacerse con el interés de la joven y, cuando su estado anímico se encuentra menos estable, la vieja vuelve a perturbar el ánimo de la joven para hablarle ahora explícitamente de Calisto, lo que, de nuevo, despierta en Melibea una reacción ciertamente expresiva que denota los diversos sentimientos que las astutas palabras de Celestina han avivado en ella:

MELIBEA.- ¡Ya, ya, ya! Buena vieja, no me digas más, no pases adelante. ¿Esse es el doliente por quien has fecho tantas premissas en tu demanda? ¿Por quien has venido a buscar la muerte para ti? ¿Por quien has dado tan dañosos passos, desuergonçada barvuda? ¿Qué siente esse perdido, que con tanta passión vienes? De locura será su mal. [...] ¡Quemada seas, alcahueta falsa, hechizera, enemiga de onestad, causadora de secretos yerros! ¡Jesú, Jesú! ¡Quítamela, Lucrecia, de delante, que me fino, que no me ha dexado gota de sangre en el cuerpo! [...] (De Rojas, 1913, pp. 178179).

Las formas de expresión de Melibea manifiestan cómo su estado ha ido siendo alterado de manera gradual a través de las precisas palabras de la vieja alcahueta, llegando éste a su cénit con los distintos improperios que la dulce Melibea dedica a la tercera. El astuto manejo de la palabra de 
Celestina ha hecho despertar en Melibea un sentimiento, la ira, pero la vieja sabe de más que ha conseguido incitar a la joven a pensar en Calisto tan sólo pronunciando su nombre justo cuando Melibea se mostraba más interesada en las palabras de Celestina. La palabra acaba así por hacerse con la estabilidad anímica de Melibea que ha sido ya embaucada por Celestina y las precisas palabras empleadas por ella en su intencionado discurso. La vieja da muestras al público, además, de la intención oculta en sus palabras en tanto que en un aparte alude a su habilidad para hacer cambiar de actitud a aquel que ella se proponga a través de la persuasión:

CELESTINA.- Tu temor, señora, tiene ocupada mi desculpa. [...] Si pensara, señora, que tan de ligero hauías de conjecturar de lo passado nocibles sospechas, no bastara tu licencia para me dar osadía a hablar en cosa, que a Calisto ni a otro hombre tocasse.

MELIBEA.- ¡Jesú! No oyga yo mentar más esse loco, saltaparedes, fantasma de noche, luengo como cigüeña, figura de paramento malpintado; si no, aquí me caeré muerta. ¡Este es el que el otro día me vido, e començó a desuariar comigo en razones, haziendo mucho del galán! [...] E tú tórnate con su mesma razón; que respuesta de mí otra no haurás ni la esperes. [...]

CELESTINA.- (Aparte.) ¡Más fuerte estaua Troya e avn otras más brauas he yo amansado! Ninguna tempestad mucho dura (De Rojas, 1913, pp. 180-182).

Lo cierto es que, si bien Celestina está haciéndose claramente con la voluntad de Melibea a través del astuto uso de la palabra precisa en su discurso, resultan aún más explícitos los efectos de la persuasión de la palabra de la vieja en oídos de Melibea en el segundo encuentro entre ambas, donde la joven ha perdido ya toda voluntad propia y se muestra perdidamente enamorada de Calisto (lejos, por tanto, del desprecio que sentía por él antes de su primer encuentro con Celestina):

MELIBEA.- Amiga Celestina, muger bien sabia e maestra grande, mucho has abierto el camino, por donde mi mal te pueda especificar. [...] Porque ni muerte de debdo ni pérdida de temporales bienes ni sobresalto de visión ni sueño desuariado ni otra cosa puedo sentir, que fuesse, saluo la alteración, que tú me causaste con la demanda, que sospeché de parte de aquel cauallero Calisto, quando me pediste la oración. [...] Tantas vezes me nombrarás esse tu cauallero, que ni mi promessa baste ni la fe, que te di, a sofrir tus dichos. [...] (De Rojas, 1913, pp. 58-63). 
Celestina ya ha conseguido apoderarse de la voluntad de la joven a través de la persuasión de sus palabras y es ahora cuando Melibea, embaucada por el discurso de la alcahueta, no teme ya nombrar a su amado de manera explícita y reconocer sus sentimientos hacia él, de hecho, recurre a Celestina para concertar una cita con su amado, lo que demuestra que se halla actuando ajena a su voluntad inicial porque la palabra que persuade al alma obliga, precisamente a este alma a la que persuade, a dejarse convencer por lo que se dice y a aprobar lo que se hace:

MELIBEA.- ¡O mi Calisto e mi señor! ¡Mi dulce e suaue alegría! Si tu coraçón siente lo que agora el mío, marauillada estoy cómo la absencia te consiente viuir. ¡O mi madre e mi señora!, haz de manera cómo luego le pueda ver, si mi vida quieres (De Rojas, 1913, p. 67).

En efecto, desde la actitud inicial de Melibea para con Calisto en el primer encuentro entre esta y Celestina, la joven muestra haber cambiado radicalmente de sentir y, si bien en principio lo ignoraba, ahora desea un encuentro físico con él. Melibea está actuando ajena a su voluntad racional, se halla apasionadamente enamorada de Calisto y todo ello debido a los efectos que la persuasión de Celestina ha producido en ella en su primer encuentro.

Mediante nuestro ejercicio intertextual ofrecemos así una nueva perspectiva analítica basada en el efecto de la persuasión de la palabra de Celestina sobre la joven, de forma que es esta, a través de su discurso, quien cautiva el oído de la joven para hacerse con su voluntad. La actitud de Melibea ofrece muchas (y diversas) interpretaciones al respecto, el cambio de voluntad de la joven hacia Calisto es ciertamente uno de los procesos más oscuros en términos hermenéuticos de toda la obra, pero si bien todas las interpretaciones intentan dar una explicación válida ante tal cambio, nosotros ofrecemos una relectura del mismo a través de los efectos de la persuasión de la palabra en el oyente recreados con detalle veinte siglos antes por el sofista de Leontinos en su discurso. Tanto si el cambio de actitud de Melibea se debe a un conjuro mágico (Puig, 1999, p. 21) como si se debe a que esta ya se hallara enamorada desde su primer encuentro con Calisto (Snow, 2001, p. 316) es evidente que las palabras que Celestina le ofrece en su primera visita alteran considerablemente su estado anímico (y, finalmente, sentimental -segundo encuentro-), por lo que huelga decir que la recreación del discurso de Celestina que ofrece Rojas en su obra da buen detalle de los efectos de la palabra precisa sobre el oyente (lo que aproximaría claramente el tratamiento de la persuasión de la palabra 
que ofrece el autor de La Celestina al tratamiento homónimo anotado por Gorgias para exculpar a Helena de su partida).

\section{Conclusiones}

El conocimiento de producciones tan dispares como un discurso griego, prueba del manejo retórico de su autor, y una obra prerrenacentista, a medio camino entre el teatro y la novela, nos ha abierto nuevos campos de análisis literario que demuestran que los textos más dispares pueden guardar más relación en su contenido que la que en principio podríamos atribuirles. El nuevo conocimiento nos invita, así, a la reflexión sobre la historia de las creaciones literarias a través del tiempo en la que, si bien mediante diferentes lenguas, materiales narrativos e intentio auctoris, el lector puede experimentar una sensación de vínculos entre su bagaje literario y las nuevas lecturas, incluso de manera pasiva y espontánea. La intertextualidad nos abre, de esta manera, un maravilloso mundo de asociaciones literarias que están ahí, esperando a ser descubiertas por una mente lectora que establezca asociaciones entre la ingente cantidad de obras artísticas universales (sin limitarnos, de hecho, a las literarias, ni siquiera a las "nacionales") para acabar dándonos cuenta que, detrás de las líneas que conforman los textos, siempre se encuentra un mismo espíritu conocedor de las mismas pasiones y temeroso de los mismos miedos manifestándose a través de la pluma de algún escritor por siglos y siglos que separen las obras. En resumidas cuentas, la persuasión de la palabra en boca Paris o de Celestina persigue, en efecto, lo mismo: hacerse con la voluntad del oyente, embaucarlo para enajenarlo de su ser, confundir al alma y hacer así que esta repruebe toda acción deseada por el hablante y, en última instancia, poseer la voluntad del engañado. En efecto, la palabra persuade, convence y engaña y despierta, así, el deseo en el oyente, fuente aristotélica de toda acción.

\section{Referencias bibliográficas}

DE ROJAS, Fernando (1913). La Celestina. Ediciones de La Lectura: Madrid.

MARTÍNEZ, Óscar (2007), “Introducción”, en Protágoras, Gorgias, Menón. EDAF: España, p. 15.

MELERO BELLIDO, Antonio (trad. y ed.) (2007). Sofistas. Obras. Editorial Gredos: España.

PUIG, María Pilar (1999), “Introducción” en DE ROJAS, Fernando. La Celestina. CEC: Venezuela, p 21. 
SECHI MESTICA, Giuseppina (2007). Diccionario Akal de mitología universal. Akal: Madrid, pp. $127-205$.

SNOW, Joseph T. (2001), “Alisa, Melibea, Celestina y la magia”, en LÓPEZ RÍOS, Santiago (ed.). Estudios sobre La Celestina. Ediciones Istmo: España, p. 316. 